\title{
Social and family factors in childhood hospital admission
}

\author{
D M FERGUSSON, L J HORWOOD, AND F T SHANNON \\ From the Christchurch Child Development Study, Department of Paediatrics, Christchurch Clinical School of \\ Medicine, Christchurch Hospital, Christchurch, New Zealand
}

SUMMARY The relation between social, economic, and family life event measures and rates of hospital admission during the period from birth to 5 years was studied in a birth cohort of New Zealand children. Both family social background and family life events made a significant contribution to the variability in the risk of hospital admission. However, economic factors made no significant contribution to rates of admission when the correlated effects of family social background and life events were taken into account. In addition, the effects of family life events on risks of admission appeared to be far more marked than the effects of family social background. Possible explanations of the consistent association between life events and rates of morbidity during early childhood are discussed.

There have been a large number of studies of the role of social factors in the aetiology of illness during childhood. At the risk of some simplification, two major groups of factors have emerged as being implicated in the risk of illness:

(a) Family social and economic situation: It has been found that rates of illness tend to be higher in families of low socioeconomic status, ${ }^{1-4}$ single parent families, ${ }^{5-7}$ families of non-Caucasian ethnic origin, 89 families in which parental education is poor, ${ }^{910}$ families with young mothers, ${ }^{11}{ }^{12}$ and families with low income or depressed living standards. ${ }^{79}$

(b) Family life events: A number of studies have suggested that rates of morbidity are increased among children in families facing various forms of stress, adversity or changing life situation. ${ }^{10}{ }^{12-19}$

However, while there have been a large number of reports of the social correlates of illness in children, most studies appear to have been conducted on cross-sectional samples or on patient populations, and there appear to be few, if any, studies that have examined the way in which family life events and family social and economic factors infiuence risks of morbidity over a protracted time period in the general child population.

We report on the results of a five year longitudinal study of rates of hospitalisation for respiratory infection, gastroenteritis, and accidents in a birth cohort of New Zealand children during their first five years. The aims of the study were twofold: (a) to document the way in which various family and social factors were associated with variations in the risk of hospitalisation during the preschool years; and

(b) to devise a proportional hazards model which? estimated the net effect of various factors on the cumulative risk of hospitalisation over time.

\section{Method}

The data were collected during the first five years of the Christchurch Child Development Study. In this study, a birth cohort of 1265 children born in the Christchurch (NZ) urban region has been studied at birth, at 4 months, and at annual intervals to the age of 5 years. At each point information has been collected by an hour-long structured interview with the child's mother supplemented by information from hospital notes, general practitioner records, and other documentary sources. ${ }^{7320}$ From the data collected in the study the following variables were selected for analysis:

(a) HOSPITAL ADMISSION FOR INFECTION AND ACCIDENTS

Information on hospital admission was collected in the following ways. Each year, mothers were supplied with a health diary record in which they were requested to record all details of any medical contact the child had made during the year. The diary 
record served as the primary source of information about health medical contacts but this was supplemented by direct questioning of the mother at each year. Once a child had been identified as having been admitted to hospital, details of the admission were obtained from the case notes and related material describing the admission. (In all cases notes were obtained following informed maternal consent.) It was possible to check maternal reporting accuracy by comparing maternal reports with the central records held at Christchurch Hospital and this showed that during the five year study period only five admissions were not reported and all of these were for relatively trivial reasons. During the five year period a total of 670 admissions occurred and admission rates show a steady tendency to decline with age, $35 \%$ occurring during the first year.

For the purposes of the present analysis, two major groups of admissions were considered:

1 admissions for pneumonia, bronchitis, bronchiolitis, croup, other respiratory infection or gastroenteritis;

2 admissions for childhood accidents including accidental poisoning and burns.

These admissions constituted $36 \%$ of the total admissions occurring during the study period and were selected on the basis of previous analysis which suggested that they were the only admission categories sensitive to social or familial conditions. ${ }^{6101213}$ Consideration was given to subdividing the data into finer diagnostic groups but this did not give sufficient numbers of observations per category to conduct a detailed analysis of the data.

\section{(b) EXPLANATORY VARIABLES}

The following variables were used in the analysis as explanatory variables.

1 Measures of family social background

i Maternal educational level classified as: mother lacked formal educational qualifications; mother had secondary educational qualifications (ie, NZ School Certificate, university entrance); mother had tertiary qualifications (university degree, tertiary professional qualifications).

ii Child's ethnic status: Maori, Pacific Island/Caucasian, other.

iii Family socioeconomic status: based on the Elley and Irving ${ }^{21}$ scale of socioeconomic status for New Zealand. This scale divides the population into six social classes on the basis of occupation.

iv Child's family placement at birth: whether the child entered an adoptive family, a (natural) two parent family or a single parent family.

v Maternal age at the birth of the child.
2 Measures of family economic situation

i Averaged family income: This was based on the average of the family's reported gross annual income during the five years study period and was converted to a rank measure to give an estimate of the mean income level experienced by the child's family during the preschool years.

ii Averaged standard of living: At each year, interviewers were asked to rate the family's material conditions on a five point scale ranging from "very good, obviously affluent" to "very poor, family obviously in poverty". To obtain an estimate of the typical material conditions of the family during the study period the interviewer ratings were summed over the five year study period and divided by five. iii Averaged financial difficulty: At each year, interviewers were asked to assess how much financial difficulty the family was facing, independently of its material living standards. An averaged rating of financial difficulty was obtained in the same way as the averaged measure of family living standards.

iv Quality of interior and exterior of the accommodation: Each year interviewers rated the quality of the interior and exterior of the child's accommodation on a five point scale ranging from "very good" to "very poor". Overall measures of quality of accommodation were obtained by averaging the ratings over the five year period.

\section{Family life events}

Each year from 2 to 5 years, mothers were interviewed on a modified version of the Holmes and Rahe Social Readjustment Rating Scale. ${ }^{22}$ This consisted of 20 items which covered such areas as death or illness in the family, changes in parent's employment, financial problems, and marital disharmony. The distributions of life events items over time and the characteristics of the scale have been described in a previous paper. ${ }^{13}$ To measure the amount of stress or adversity faced by the family, four life events scores were created using a simple sum of the number of life events reported during the periods 1-2 years, 2-3 years, 3-4 years, and 4-5 years. A simple count of the number of life events was used in preference to a weighted score of these measures since previous analysis ${ }^{13}$ had shown that the unweighted sum was highly correlated $(r=0.96)$ with the weighted sum. This implies that the amount of information provided by weighting items in terms of their "importance" was negligible. The unweighted sum was used in the analysis as it was simpler to interpret.

SAMPLE SIZE

The analysis is based on a sample of 1057 children for whom complete data on all variables were available. 
This sample represents $84 \%$ of the initial cohort of 1265 children and $94 \%$ of the children who remained alive and resident in New Zealand to 5 years. To examine whether the sample was biased as a result of losses to follow up, the social and demographic characteristics of the initial sample were compared with those of the sample participating at 5 years. This analysis showed no significant association between losses to follow up (including postnatal death) and the child's social or perinatal characteristics.

\section{Results}

ASSOCIATIONS BETWEEN RATES OF HOSPITAL ADMISSION, FAMILY SOCIAL POSITION, FAMILY ECONOMIC CIRCUMSTANCES, AND FAMILY LIFE EVENTS

Table 1 shows rates of hospital admission (per 100 children aged $0-5$ years) for respiratory illness, gastroenteritis, and accidents cross-tabulated by a series of measures of family social position, family economic circumstances, and family life events. Each comparison is tested for statistical significance using an F statistic based on the square root transformation of the rate data. The results show:

1 There was a clear tendency for children from socially disadvantaged backgrounds to experience higher rates of admission. As a general rule, children of Polynesian ethnic status, children from single parent families, children of poorly educated mothers, children of young mothers, and children from families of low socioeconomic status had the greatest risk of admission for both accidents and infections. 2 Rates of admission varied with family economic and material circumstances, children from low income families and from families with depressed material conditions being at greater risk of hospital . admission.

3 There was a consistent trend for rates of hospital admission to increase with the number of life events reported by the child's mother each year.

DATA REDUCTION AND PROPORTIONAL HAZARDS ANALYSIS

The results in table 1 strongly suggest that rates of hospital admission were highest among children from socially disadvantaged, economically deprived and stressed families. However, the analysis does not show the net contributions of these factors to the variability in the rates of admission. To examine this a proportional hazards model was fitted to the data. (A detailed account of the theoretical and mathematical basis of this model may be found in $\mathrm{Cox}^{23}$ and Kalbfleisch and Prentice. ${ }^{24}$ However, before this analysis the extensive social and economic data in table 1 were reduced to two general measures:
Table 1 Mean number of hospital admissions per 100 children (birth to 5 years) for infections and accidents by measures of family social position, family economic situation, and family life events

\begin{tabular}{|c|c|c|c|c|}
\hline Variable & $N$ & $\begin{array}{l}\text { Infections } \\
(A)\end{array}$ & $\begin{array}{l}\text { Accidents } \\
\text { (B) }\end{array}$ & $\begin{array}{l}\text { Total } \\
(A+B)\end{array}$ \\
\hline \multicolumn{5}{|l|}{ Family social position } \\
\hline $\begin{array}{l}\text { Maternal age }(y r) \\
15-19 \\
20-24 \\
25-29 \\
30-34 \\
35+\end{array}$ & $\begin{array}{r}97 \\
323 \\
417 \\
165 \\
55\end{array}$ & $\begin{array}{r}25 \cdot 8 \\
16 \cdot 7 \\
9.6 \\
8 \cdot 5 \\
7 \cdot 3\end{array}$ & $\begin{array}{r}18.6 \\
14.2 \\
4.8 \\
11.5 \\
1.8\end{array}$ & $\begin{array}{r}44 \cdot 3 \\
31 \cdot 0 \\
14 \cdot 4 \\
20 \cdot 0 \\
9 \cdot 1\end{array}$ \\
\hline $35+$ & & $\mathrm{p}<0.01$ & $\mathrm{p}<0.001$ & $\mathrm{p}<0.0001$ \\
\hline $\begin{array}{l}\text { Maternal education } \\
\text { No formal qualifications } \\
\text { Secondary qualifications } \\
\text { Tertiary qualifications }\end{array}$ & $\begin{array}{l}546 \\
306 \\
205\end{array}$ & $\begin{array}{r}16 \cdot 9 \\
9 \cdot 2 \\
8 \cdot 3\end{array}$ & $\begin{array}{r}9 \cdot 9 \\
12 \cdot 8 \\
5 \cdot 4\end{array}$ & $\begin{array}{l}26 \cdot 7 \\
21 \cdot 9 \\
13 \cdot 7\end{array}$ \\
\hline Tertiary qualifications & & $p<0.05$ & NS & $p<0.05$ \\
\hline \multicolumn{5}{|l|}{ Ethnic status of child } \\
\hline \multirow[t]{2}{*}{ Caucasian, other } & $\begin{array}{l}155 \\
902\end{array}$ & $\begin{array}{l}19 \cdot 4 \\
11 \cdot 9\end{array}$ & $\begin{array}{r}18 \cdot 7 \\
8 \cdot 3\end{array}$ & $\begin{array}{l}38 \cdot 1 \\
20 \cdot 2\end{array}$ \\
\hline & & $\mathrm{p}<0.05$ & $\mathrm{p}<0.01$ & $p<0.01$ \\
\hline \multicolumn{5}{|l|}{ Birth status } \\
\hline $\begin{array}{l}\text { Adopted } \\
\text { Two parents } \\
\text { Single parent }\end{array}$ & $\begin{array}{r}36 \\
946 \\
75\end{array}$ & $\begin{array}{r}5 \cdot 6 \\
11 \cdot 7 \\
32 \cdot 0\end{array}$ & $\begin{array}{r}2 \cdot 8 \\
9 \cdot 1 \\
22 \cdot 7\end{array}$ & $\begin{array}{r}8 \cdot 3 \\
20 \cdot 8 \\
54 \cdot 7\end{array}$ \\
\hline Single parent & & $p<0.001$ & $\mathrm{p}<0.01$ & $\mathrm{p}<0.0001$ \\
\hline \multicolumn{5}{|l|}{ Socioeconomic status } \\
\hline $\begin{array}{l}\text { Professional, executive } \\
\text { Skilled, clerical }\end{array}$ & $\begin{array}{l}217 \\
565\end{array}$ & $\begin{array}{r}6.9 \\
12.6\end{array}$ & $\begin{array}{r}5 \cdot 5 \\
10 \cdot 6\end{array}$ & $\begin{array}{l}12 \cdot 4 \\
23 \cdot 2\end{array}$ \\
\hline \multirow[t]{2}{*}{$\begin{array}{l}\text { Semiskilled, unskilled, } \\
\text { unemployed }\end{array}$} & 275 & $18 \cdot 6$ & $11 \cdot 6$ & $30 \cdot 2$ \\
\hline & & $p<0.05$ & NS & $p<0.01$ \\
\hline
\end{tabular}

Economic and material conditions

\begin{tabular}{|c|c|c|c|c|}
\hline \multicolumn{5}{|l|}{ Standard of living } \\
\hline Above average & 178 & $10 \cdot 7$ & $5 \cdot 6$ & $16 \cdot 3$ \\
\hline Average & 826 & $12 \cdot 1$ & $9 \cdot 0$ & $21 \cdot 1$ \\
\hline \multirow[t]{2}{*}{ Below average } & 53 & $34 \cdot 0$ & $37 \cdot 7$ & $71 \cdot 7$ \\
\hline & & $p<0.01$ & $\mathrm{p}<0.0001$ & $p<0.0001$ \\
\hline \multicolumn{5}{|l|}{ Family income } \\
\hline Upper quintile & 205 & $9 \cdot 5$ & $4 \cdot 4$ & $13 \cdot 9$ \\
\hline Second quintile & 211 & $6 \cdot 1$ & $7 \cdot 5$ & 13.6 \\
\hline Third quintile & 211 & $17 \cdot 1$ & $8 \cdot 8$ & $25 \cdot 9$ \\
\hline Fourth quintile & 214 & $12 \cdot 6$ & $11 \cdot 7$ & $24 \cdot 2$ \\
\hline \multirow[t]{2}{*}{ Lower quintile } & 216 & $18 \cdot 0$ & $14 \cdot 6$ & $32 \cdot 6$ \\
\hline & & $p<0.01$ & $\mathrm{p}<0.05$ & $\mathrm{p}<0.01$ \\
\hline \multicolumn{5}{|l|}{ Financial difficulty } \\
\hline Obviously had no difficulty & 246 & $8 \cdot 1$ & $4 \cdot 5$ & $12 \cdot 6$ \\
\hline Unlikely to have difficulty & 739 & $13 \cdot 7$ & $9 \cdot 5$ & $23 \cdot 1$ \\
\hline \multirow[t]{2}{*}{ Probably having difficulty } & 72 & $22 \cdot 2$ & $31 \cdot 9$ & $54 \cdot 2$ \\
\hline & & $p<0.05$ & $p<0.0001$ & $\mathrm{p}<0.0001$ \\
\hline \multicolumn{5}{|l|}{ Quality of interior of house } \\
\hline Obviously affluent & 48 & $8 \cdot 3$ & $6 \cdot 3$ & $14 \cdot 6$ \\
\hline Very good & 363 & $9 \cdot 4$ & $8 \cdot 0$ & $17 \cdot 4$ \\
\hline Average & 575 & 13.9 & $9 \cdot 0$ & $23 \cdot 0$ \\
\hline \multirow[t]{2}{*}{ Below average } & 71 & $26 \cdot 8$ & $28 \cdot 2$ & $54 \cdot 9$ \\
\hline & & $\mathrm{p}<0.05$ & $p<0.0001$ & $p<0.0001$ \\
\hline \multicolumn{5}{|l|}{ Quality of exterior of house } \\
\hline Obviously affluent & 41 & $12 \cdot 2$ & $4 \cdot 9$ & $17 \cdot 1$ \\
\hline Very good & 345 & $7 \cdot 5$ & $7 \cdot 5$ & $15 \cdot 1$ \\
\hline Average & 610 & 14.9 & $9 \cdot 2$ & $24 \cdot 1$ \\
\hline Below average & 61 & $24 \cdot 6$ & $32 \cdot 8$ & $57 \cdot 4$ \\
\hline
\end{tabular}

$\mathrm{p}<0.01 \quad \mathrm{p}<0.0001 \quad \mathrm{p}<0.0001$ 
Table 1-continued

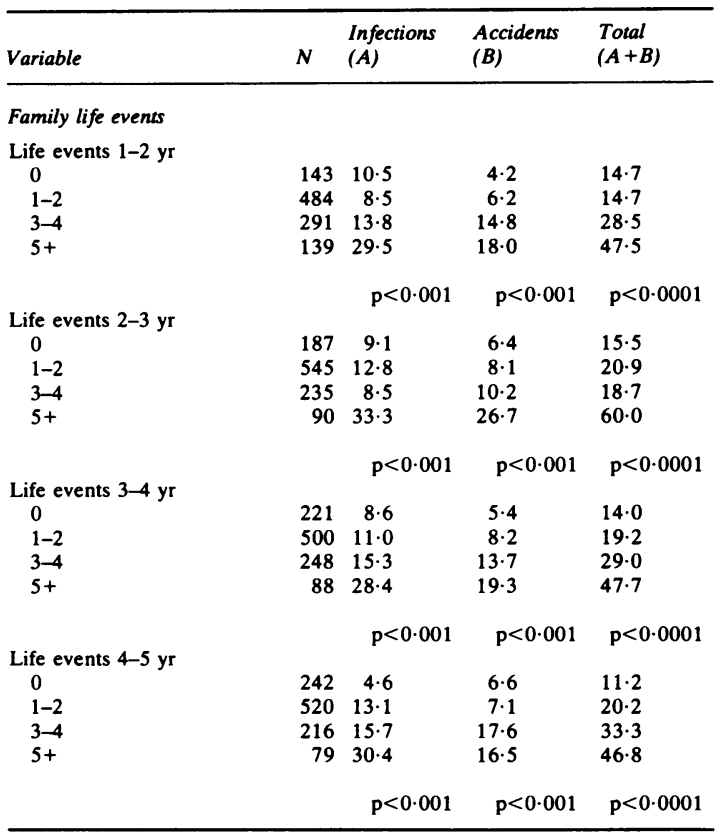

1 Family social position This was a weighted linear combination of the measures of maternal age, maternal education, ethnicity, the child's birth placement, and family socioeconomic status. This weighted sum defined a general dimension which ranged from extremely socially disadvantaged families (ie, those with a young mother of poor education, of Polynesian ethnicity, in which the child entered a single parent, low socioeconomic status family at birth) to extremely highly advantaged families (ie, those with an older mother with tertiary education, of Caucasian ethnicity, where the child entered a two parent family of professional socioeconomic status).

2 Family economic background This was a weighted linear combination of the measures of family income, family living standards, and family housing conditions. The measures defined a general dimension of economic material well-being which ranged from families with low income and poor living standards and housing conditions to families with high income and superior housing and living conditions.

These indices were obtained by factor analysing the variables and using the least squares estimates of the factor score coefficients to obtain an estimate of the underlying dimension. A detailed account of the method of scale construction has been given in a previous paper..$^{25}$ There were three major reasonings for reducing the data in this way:

(a) Since the emphasis of the study was on the effects of broad social and related differences between families, it was felt that composite measures of social and economic conditions would provide more robust and interpretable measures of the general aspects of family functioning.

(b) A number of the explanatory variables in table 1 were highly intercorrelated, and this could raise serious problems of multicollinearity in an analysis in which the original raw data were entered. By reducing the data into general indices based on sets of intercorrelated variables many of these problems were reduced.

(c) The proportional hazards model described below includes a dynamic time dependent covariate, and preliminary investigation suggested that with such a variable it was not possible to enter all explanatory variables into the model if the original raw data were analysed. By combining variables into more general indices, the demands on the available computing space were reduced to manageable dimensions.

However, while the reduction of the social and economic data to broad indices has a number of obvious theoretical and practical advantages, there was a possibility that such classification could distort the results. To examine this a number of exploratory multiple regression analyses were conducted to compare the predictive power of the combined measures with that of the original raw data. This analysis suggested that combining social and economic variables into more general indices had a negligible effect on the predictive power of the data.

Table 2 shows the results of fitting a proportional hazards model to the risk of at least one hospital admission for accident or infection during the five year study period. In this model the explanatory variables were the fixed covariates of family social position and economic situation and the time dependent covariate of family life events. (In a time dependent analysis the values of the covariates are permitted to change throughout the period being studied. A more detailed discussion of the properties of such covariates is provided by Kalbfleisch and Prentice $\left.{ }^{24}\right)$. The model fitted was:

$$
\lambda(z ; t)=\lambda_{0}(t) e^{z_{1} \beta_{1}+z_{t} \beta_{2}}
$$

where $\lambda(z ; t)$ denotes the hazard or instantaneous rate of hospitalisation at time $t$ for a subject with covariate vector $z$. In this instance the vector $z$ comprises the set of fixed covariates $z_{1}$ and the set of time dependent covariates $z_{2}$ measured at time $t$. $\lambda_{o}(t)$ denotes the hazard which exists for the base line population with covariate values of 0 at time $t$, and $\beta_{1}, \beta_{2}$ are a set of regression like coefficients which show the extent to 
which the hazard for a subject with a non zero covariate vector is increased when compared to the hazard for the base populations.

The table is divided into two major sections.

The first section shows maximum likelihood estimates of the regression coefficients of the model and their standard errors. This information makes it possible to test the significance of the net effects of each of the explanatory variables on the variation in rates of hospital admission. The results show that family social position $(t=3.07 ; p<0.01)$ and family life events $(t=3.88 ; p<0.001)$ were significantly related to rates of hospital admission. However, family economic situation was not a significant predictor $(t=0.57 ; p>70.50)$. This implies that the apparent correlations between family economic conditions and rates of admission arose largely from the correlations of this measure with family social position and family life events.

The second part of the table shows the estimated proportional hazards coefficients. These may be interpreted in a way that is analogous to the more familiar notion of relative risk: the increase in the hazard or instantaneous rate of hospital admission which is associated with a given level of an explanatory variable when compared to the risk that exists for a defined base line population. In this instance the base line population is the group of children in the top quartile of the social position measure whose families reported one or fewer life events in any given year. The findings show a clear tendency for decreasing social position to be associated with increasing risks of admission, and children who were in the lowest quartile of the population had nearly twice the rate of admission as children in the base line population. Similarly, there is a marked tendency for risks of admission to increase with increasing reports of life events, and for any year children whose families reported five or more life events were 2.7 times more likely to be admitted to hospital.

While the results in table 2 show the relative risks of admission for various groups of subjects, they do not indicate the overall levels of admission for groups with varying combinations of covariate values. To do this requires estimation of the survival curves (ie, the proportions of subjects not admitted to hospital over time) for various covariate values. However, estimation of survival curves for the life events measure is complex, since this measure was treated as a time dependent covariate with the result that rates of survival are conditional on the pattern of life events reporting over the five year period. To produce estimates of the survival curves an approximate method was therefore used. This involved computing, for each child, the average
Table 2 Results of proportional hazards model

(a) Fitted regression coefficients

\begin{tabular}{lllll}
\hline Variable & Coefficient & $S E$ & $t$ & $p$ \\
\hline Family life events & 0.330 & 0.086 & 3.88 & $<0.001$ \\
Family social position & 0.229 & 0.075 & 3.07 & $<0.01$ \\
Family economic situation & 0.051 & 0.089 & 0.57 & $>0.50$ \\
\hline
\end{tabular}

(b) Proportional hazards coefficients for levels of significant variables

\begin{tabular}{ll}
\hline Variable & $e^{z \beta}$ \\
\hline Family life events & 1 \\
$\quad$ No events & 1.397 \\
$1-2$ events & 1.952 \\
3-4 events & 2.726 \\
5+ events & \\
Family social position & 1 \\
$\quad$ Top quartile & 1.257 \\
Second quartile & 1.580 \\
Third quartile & 1.986 \\
Bottom quartile & \\
\hline
\end{tabular}

hazard score for the life events history he or she experienced throughout the five year study periodo The averaged hazard was defined as:

$$
\lambda(t ; z)=\lambda_{o}(t) \Sigma e^{z \beta} / 4
$$

where $\mathrm{e}^{\mathrm{z} \beta}$ was evaluated for the life events measure af each of the four time periods studied. It will be noted that since $\lambda_{\mathrm{o}}(\mathrm{t}), \beta$, and $\mathrm{e}$ are known constants for an time $t$, the averaged hazard is proportional to the average number of life events reported per year of alternatively, to the accumulated number of life events that the family reported.

Figures 1 and 2 show the proportion of children not admitted to hospital for infection or accidents over the five year study period subdivided by both the social position score and the averaged hazard score. The comparisons are shown in two forms:

(i) The unadjusted results are the observed survivorship curves for each of the groups.

(ii) The adjusted curves are the estimated survivorship curves, taking into account the intercorrelations of family life events and the family social position. The adjusted curves were obtained by: (a) stratifying the sample on the basis of each factor; (b) solving the theoretical survival curves for each stratum; and (c) combining the resulting theoretical curves to produce overall adjusted curves using a weighted average of the estimates.

Inspection of figs 1 and 2 suggests two major conclusions:

(i) The effects of adjusting the curves for the $N$ intercorrelation of life events and the family social position is to reduce the overall effects of each factor on rates of admission. Before adjustment, children whose families reported an average of five or more 2 life events per year had rates of admission by five 
(a)



(b)

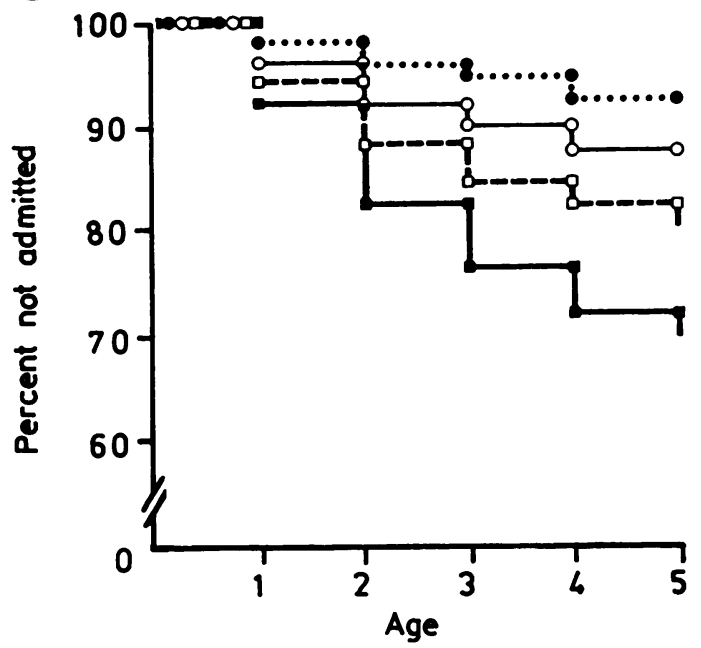

Fig 1 Cumulative proportions of children not admitted to hospital by a given age for varying levels of the mean number of life events per annum (a) unadjusted for the effects of family social position and (b) adjusted for the effects of family social position:

01 life event per annum; $\quad 1-2$ life events per annum.

$\square 3-4$ life events per annum; $\square+$ life events per annum.

(a)



(b)

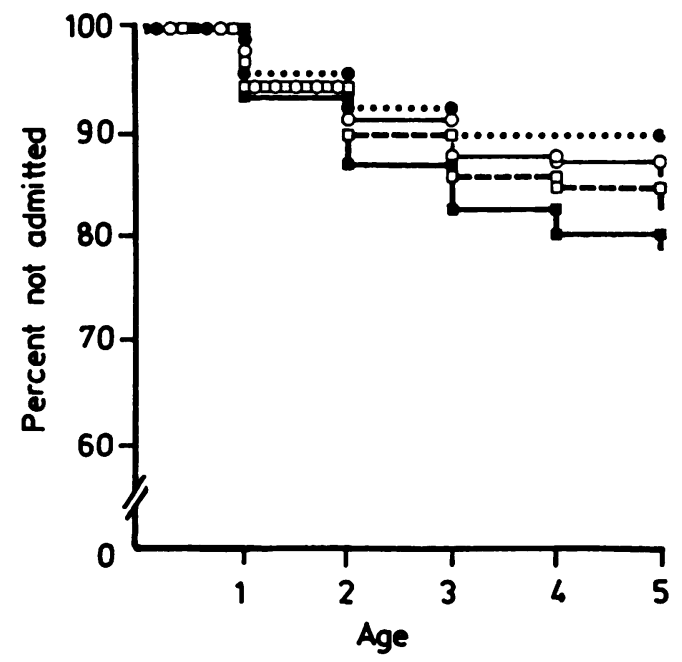

Fig 2 Cumulative proportions of children not admitted to hospital by a given age for quartiles of the family social position index (a) unadjusted for the effects of family life events and (b) adjusted for the effects of family life events: 
years which were nearly five times higher than those whose families reported an average of less than one event per year (39\% versus $8 \%$ respectively). After adjustment for the common effects of family social position this difference reduced to 3 to 1 (29\% versus $9 \%$ respectively). Similar trends are present for the social position measure: before adjustment for family life events children in the lowest quartile of the distribution had five year admission rates which were nearly $2 \frac{1}{2}$ times those in the top quartile (24\% versus $10 \%$ respectively); after adjustment this difference reduced to $1 \cdot 8$ to 1 ( $21 \%$ versus $12 \%$ respectively). (ii) In terms of the contribution to the variability in rates of admission it is apparent from both the unadjusted and adjusted curves that the family life events variable makes a greater contribution than the social position measure.

\section{Discussion}

The findings of this research confirm the results of previous studies of the social aetiology of childhood morbidity: ${ }^{1-19}$ rates of hospitalisation were highest among children from socially disadvantaged families, economically depressd families, and families facing various forms of stress and adversity. However, the longitudinal nature of the data and associated analysis serve to place a number of important issues into perspective.

Firstly, it is often implicitly assumed that "poverty" is one of the major social determinants of hospital admission and ill health in children. However, the findings here indicate that family economic and material conditions made no significant contribution to the variability in rates of hospital admission when the correlated factors of family social background and family life events were taken into account. This suggests that the apparent correlations between family material and economic conditions and hospital admission arise because both higher rates of morbidity and depressed economic circumstances are symptomatic of a socially disadvantaged or stressed family environment. Of course, this conclusion holds true only for the range of social conditions in the population under study, and the effects of poverty on child health in underdeveloped Third World countries are well known. What the findings indicate is that in a relatively economically homogeneous society, such as New Zealand, economic factors play little role in the aetiology of hospital admission once the effects of family social background and family life events are taken into account.

It is also often assumed that social class or socioeconomic status is the major social determinant of hospital admission. However, the findings here show very clearly that family life events made a consistently larger contribution to the variability in rates of illness than family social background factors. This observation has been noted in previous studies of this cohort. ${ }^{101213}$ This perhaps suggests that in a society such as New Zealand variations in intra-family dynamics make a greater contribution to the risk of childhood illness than broad differences in terms of family social or demographic factors.

The persistent correlations between life events measures and child health seen in this research and other studies ${ }^{102-19}$ raise a number of important questions about the mechanisms by which life events are related to childhood illness. Broadly speaking, there appear to be three major explanatory hypotheses which could account for the associations.

(a) MEASUREMENT ERROR AND RESPONDENT BIAS

It is possible that the apparent correlations between life event reports and rates of illness arise from a series of measurement errors or biases. In particular, it is possible that while life events do not alter illness they may alter health care seeking behaviour so that families under stress or making social readjustments may seek medical attention more often than other families. This is a difficult issue to resolve since almost invariably measures of morbidity are based on medical attendance. However, it is perhaps worth noting that if such bias does exist it appears to apply not only to hospital admission but to other types of medical attendance since a previous study of this cohort has found similar correlations between general practitioner attendances, hospital outpatient attendance, and life events. ${ }^{13}$ It is also possible that mothers whose children have been admitted to hospital may invent or over-report life events in an attempt to explain the reason for the hospitalisation. For the present data this seems unlikely since the life events chosen for study related to common and major problems-health problems in the family, financial problems, marital problems, bereavement, family conflicts (see Beautrais, Fergusson and Shannon ${ }^{13}$ ) which would have been hard to invent or over-report.

(b) CHANGES IN SUSCEPTIBILITY TO ILLNESS The higher rate of hospitalisation for infection among children from families reporting high levels of life events leads to the speculation that perhaps children in these families have a greater susceptibility to illness due to a transient immunodeficiency caused by stress and readjustment in the family. There have been a number of tantalising hints that this may be the case. Meyer and Haggerty, ${ }^{17}$ in a study of streptococcal sore throats in children, found that the onset of illness was often preceded by a significant 
family life event. Further, a series of studies have suggested changes in catecholamines, corticosteroids, and immune function in subjects facing various forms of stress and difficulty. ${ }^{26-31}$ It may be hypothesised that stress leads to an increased catecholamine and corticosteroid production which inhibits immune function ${ }^{27-29}$ which in turn leads to greater rates of morbidity. ${ }^{26}{ }^{30}{ }^{31}$ While the available evidence tends to be consistent with this hypothesis, critical evidence linking life events to changes in immune function and thence to greater risks of infection is still lacking.

\section{(c) CHANGES IN PARENTING BEHAVIOUR}

While it is possible that the greater rates of infection in children in families reporting significant life events may be explained by a change in immune function, such an explanation cannot be applied to the persistent correlations that have been found between family life events and childhood accidents. ${ }^{1012} 141619$ It seems more likely that this correlation arises because of changes in parenting behaviour which place the child at greater risk from various environmental hazards. In particular, it seems likely that in families facing readjustment, parental vigilance and care of children may be reduced, leading to a greater risk of accidents. ${ }^{12}$ However, again critical evidence linking life events to a change in parenting behaviour and thence to a change in the hazards faced by the child is not yet available.

Life events research has been an area that has been extremely controversial, and opinions have tended to polarise into an uncritical acceptance of the view that life events cause morbidity to an over critical rejection of this view. ${ }^{32} \mathrm{~A}$ more realistic assessment of the field is that there have been a large number of correlations reported between life event measures and various measures of morbidity. These correlations have not been explained adequately either by the critics who espouse the view that they arise from measurement error or the enthusiasts who assume that they reflect causal associations. Clearly there is still much to be learned about the way in which adversity and readjustment in the lives of people influence their health and well-being. A major aim of this paper has been to show that, of the social factors implicated in hospital admission during the preschool years, family life events appear to exert by far the most persistent and consistent influence on admission rates.

This research was funded by grants from the Medical Research Council of New Zealand and the National Children's Health Research Foundation.

\section{References}

${ }^{1}$ Taylor B, Wadsworth J, Golding J, Butler N. Breastfeeding, bronchitis and admissions to hospital for lower respiratory illness and gastroenteritis during the first five years. Lancet 1982; i: 1227-9.

${ }^{2}$ Scott HD, Mackie A. Decisions to hospitalise and to operate: a socioeconomic perspective in an urban state. Surgery 1975; 77: 311-7.

${ }^{3}$ Colley JRT, Reid DD. Urban and social origins of childhood bronchitis in England and Wales. Br Med J 1970; 2: 213-7.

${ }^{4}$ Miller FJW, Court SDM, Walton WS, Knox EG. Growing up in Newcastle upon Tyne: a continuing study of health and illness in young children within their families. London: Oxford University Press, 1960.

${ }^{5}$ Wadsworth J, Burnell I, Taylor B, Butler N. Family type and accidents in preschool children. $J$ Epidemiol Community Health 1983; 37: 100-4.

${ }^{6}$ Fergusson DM, Horwood LJ, Shannon FT. Birth placement and child health. $N Z$ Med J 1981; 93: 37-41.

${ }^{7}$ Fergusson DM, Horwood LJ, Shannon FT. Birth placement and childhood disadvantage. Soc Sci Med 1981; 15E: 315-26.

${ }^{8}$ Fergusson DM, Horwood LJ, Shannon FT. Family ethnic composition, socioeconomic factors and childhood disadvantage. NZ J Educ Studies 1982; 17: 171-9.

${ }^{9}$ O'Donnell JL, Fergusson DM, Horwood LJ, Shannon FT. Health care in early infancy. NZ Med J 1978; 88: 315-7.

${ }^{10}$ Beautrais AL, Fergusson DM, Shannon FT. Childhood accidents in a New Zealand birth cohort. Aust Paed J 1982; 18: 238-42.

1 Taylor B, Wadsworth J, Butler NR. Teenage mothering: hospitalisation and accidents during the first five years. Arch Dis Child 1983; 58: 6-11.

${ }^{12}$ Beautrais AL, Fergusson DM, Shannon FT. Accidental poisoning in the first three years of life. Aust Paed J 1981; 17: 104-9.

${ }^{13}$ Beautrais AL, Fergusson DM, Shannon FT. Life events and childhood morbidity: a prospective study. Pediatrics 1982; 70: 935-40.

${ }^{14}$ Padilla ER, Rohsenow DJ, Bergman AB. Predicting accident frequency in children. Pediatrics 1976; 58: 223-6.

${ }^{15}$ Heisel JS, Ream S, Raitz R, et al. The significance of life events as contributing factors in diseases of children. $J$ Pediatr 1973; 88: 119-23.

${ }^{16}$ Meyer RJ, Roelefs HA, Bluestone J, et al. Accidental injury to the preschool child.J Pediatr 1963; 63: 95-105.

${ }^{17}$ Meyer RJ, Haggerty RJ. Streptococcal infections in families: factors altering individual susceptibility. Pediatrics 1962; 29: 539-49.

${ }^{18}$ Boyce WT, Jensen W, Cassel JC, Collier AM, Smith AH, Ramey CI. Influence of life events and family routines on childhood respiratory tract illness. Pediatrics 1977; 60: 609-15.

${ }^{19}$ Sibert R. Stress in families of children who have ingested poisons. Br Med J 1975; 3: 87-9.

${ }^{20}$ Beautrais AL, Fergusson DM, Shannon FT. Family life events and behavioural problems in preschool-aged children. Pediatrics 1982; 70: 774-9.

${ }^{21}$ Elley WB, Irving JC. Revised socioeconomic index for New Zealand. NZ $J$ Educ Studies 1976; 1: 25-36.

${ }^{22}$ Holmes TH, Rahe RH. The social readjustment rating scale. J Psychosom Res 1967; 11: 213-8.

${ }^{23}$ Cox DR. Regression models and life tables (with discussion). J Royal Stat Soc B, 1972; 34: 187-220.

${ }^{24}$ Kalbfleisch JD, Prentice RL. The statistical analysis of failure time data. New York: John Wiley, 1980. 
${ }^{25}$ Fergusson DM, Dimond ME, Horwood LJ, Shannon FT. The utilisation of preschool health and education services. Soc Sci Med 1984; 19: 1173-80.

${ }^{26} \mathrm{Jemmott} \mathrm{JB}$, Borysenko JZ, Borysenko $\mathrm{M}$, et al. Academic stress, power motivation, and decrease in secretion rates of salivary secretion immunoglobulin $\mathrm{A}$. Lancet 1983; i: 1400-3.

${ }^{27}$ Rogers MR, Dubey D, Reich P. The influence of the psyche and the brain on immunity and disease susceptibility: a critical review. Psychosom Med 1979; 41: $147-64$.

${ }^{28}$ Borysenko $M$, Borysenko J. Stress, behaviour and immunity: animal models and mediating mechanisms. Gen Hosp Psychiatry 1982; 4: 59-67.

${ }^{2 y}$ Ader R, ed. Psychoneuroimmunology. New York: Academic Press, 1981.

${ }^{30}$ Bartrop RW, Lazarus L, Lockhurst E, et al. Depressed lymphocyte function after bereavement. Lancet 1977; i: 834-36.

${ }^{31}$ Dorian BJ, Keystone W, Garfinkel PE, Brown CM. Immune mechanisms in acute psychological stress. Psychosom Med 1981; 43: 84 (abstr).

${ }^{32}$ Dohrenwend BS, Dohrenwend BP, eds. Stressful life events: their nature and effects. New York: John Wiley, 1974. 